\title{
The Research of Outdoor Fitness Facilities Design Based on Kano Model
}

\author{
Xiyin Gao, Chunrong Zhao and Yue Han \\ Agricultural University of Hebei, Baoding, China
}

\begin{abstract}
With the improvement of person's health consciousness, exercise time corresponding increase, more and more people are favour of outdoor fitness facilities, new demands to outdoor fitness facilities come up. Though the investigating and analyzing user's feelings to current outdoor fitness facilities and potential demand to a new design based on Kano model, this paper focuses on determining new demands and the key needs demands by using the three essential factors, expectation factor and charming factor. Starting from the needs of users of different levels, this paper puts forward three fitness facilities design thoughts, that is the human-computer interaction, interpersonal function and special fitness equipment development, and take the solar interactive fitness facilities, parenting fitness facilities, the practical design of children's fitness facilities for practice, which provide design basis for development of outdoor fitness facilities design.
\end{abstract}

Keywords- product design; outdoor fitness facilities; the kano model; interaction design

\section{INTRODUCTION}

With the promulgation and implementation of the "National Fitness Program (2011-2015)" and the "National Fitness Program (2016-2020)", the mass fitness movement is at an all-time high. Outdoor fitness facilities get the favour of fitness people because of convenience, openness and diversification. Its manufacturing industry has been developing rapidly. However, because of the absence of systematic and comprehensive normative standards, the fitness facilities have many problems in function, shape, manmachine factors, entertainment and other aspects ${ }^{[1]}$. We found in the satisfaction survey that the change of fitness crowd, the way of fitness and physical fitness led that the existing fitness facilities function has been unable to meet the new requirements of the fitness crowd. Therefore, the Kano model will be applied to outdoor fitness facilities design. The purpose is through the Kano model to excavate the new appeals of the fitness crowd for outdoor fitness facilities, and to analyse the important demands of the fitness crowd satisfaction, and then to determine the design ideas. This will provide the basis for developing outdoor fitness facilities of meeting different people.

\section{USER REQUIREMENT ANALYSIS BASED ON KANO MODEL}

Kano model, founded in 1984 by Professor Noriaki Kano of Tokyo Polytechnic University, has been widely used and promoted in the field of product design. The purpose is to understand and distinguish the needs of users of different levels, so as to identify the important factors which make customer satisfy, and find the breakthrough point of improving customer satisfaction in product development. According to the relationship between product's objective performance and user subjective perception, Kano model divides the factors which influence user satisfaction into three types: charm factor, expected factor ,essential factor ${ }^{[2]}$.

\section{A. Researching Crowd Needs for Outdoor Fitness Facilities}

The use of fitness facilities in some communities and parks in Baoding, Hebei province was investigated. According to table 1, the user's demands and feelings were researching with interviews, questionnaires and so on, we investigate mainly from outdoor fitness facilities for the crowd, fitness time, fitness function, fitness effect, fitness methods, safety, comfort, modeling and other aspects. We survey and evaluate the fitness facilities for fitness people, and fill the Kano evaluation form with the answers of the positive and negative questions about the quality of the needs of the fitness crowd. This will determine the demands of the fitness crowd.

TABLE I. KANO EVALUATION FORM

\begin{tabular}{|c|c|c|c|c|c|c|}
\hline \multirow{2}{*}{\multicolumn{2}{|c|}{$\begin{array}{c}\text { User attitudes } \\
\text { to require }\end{array}$}} & \multicolumn{5}{|c|}{ This function is not available } \\
\hline & & $\begin{array}{l}\text { Lov } \\
\mathrm{e}\end{array}$ & $\begin{array}{l}\text { Taken } \\
\text { for } \\
\text { granted }\end{array}$ & $\begin{array}{c}\text { Indiffere } \\
n t\end{array}$ & $\begin{array}{l}\text { Accepting } \\
\text { reluctantly }\end{array}$ & Dislike \\
\hline \multirow{5}{*}{$\begin{array}{l}\text { With this } \\
\text { function }\end{array}$} & Love & - & A & A & A & $\mathrm{O}$ \\
\hline & $\begin{array}{c}\text { taken for } \\
\text { Granted }\end{array}$ & $\mathrm{R}$ & I & I & I & M \\
\hline & Indifferent & $\mathrm{R}$ & I & I & I & M \\
\hline & $\begin{array}{l}\text { Accepting } \\
\text { Reluctantly }\end{array}$ & $\mathrm{R}$ & I & I & I & M \\
\hline & Dislike & $\mathrm{R}$ & $\mathrm{R}$ & $\mathrm{R}$ & $\mathrm{R}$ & - \\
\hline
\end{tabular}

\section{B. Kano Model Analysis}

Initial research findings show that fitness crowds have several requirements for outdoor fitness facilities. We do further research from two aspects which can meet this demand or not and offer five options: "like", "take for granted", "do not matter", "barely accept", "do not like"[2]. The selection results are analyzed by the Kano model, as shown in figure I. 


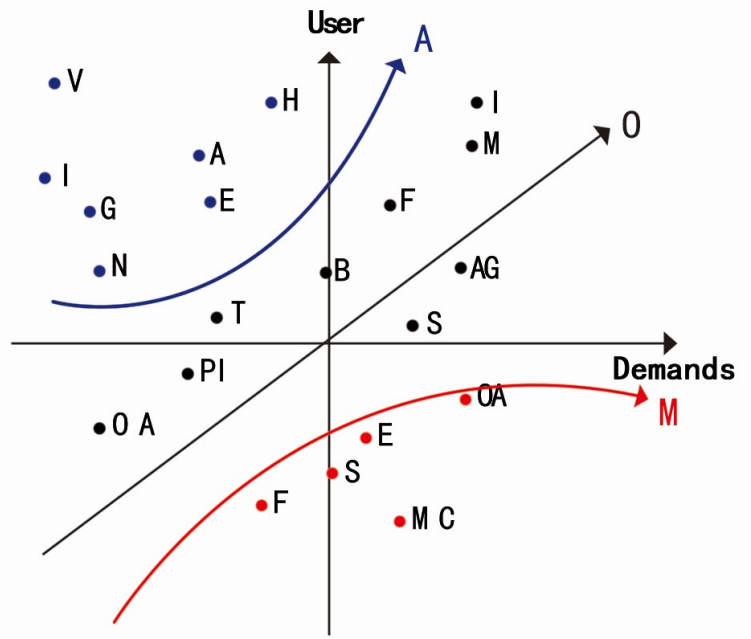

FIGURE I. THE KANO MODEL ANALYSIS DIAGRAM OF OUTDOOR FITNESS FACILITIES

The satisfaction of the demand is the horizontal axis, the user satisfaction is the vertical axis, and all the requirements are analyzed. The letters in the figure I are abbreviations, and their meanings are listed in table II below.

TABLE II. ABBREVIATIONS

\begin{tabular}{|c|c|}
\hline Abbreviations & Representative meaning (demand) \\
\hline V & Virtual coach \\
\hline I & Information sharing \\
\hline G & Remote guidance \\
\hline N & Optelligent networking \\
\hline OA & Movement analysis \\
\hline A & Energy recovery \\
\hline E & Time display \\
\hline T & Put items \\
\hline PI & Heart rate monitoring \\
\hline H & Beautiful shape \\
\hline B & information feedback \\
\hline F & Interaction \\
\hline I & Music playing \\
\hline M & Suitable \\
\hline S & Applicable to different groups \\
\hline AG & Firm and solid \\
\hline FS & Simple structure \\
\hline SS & Easy to use \\
\hline E & Comfortable operation \\
\hline OA & Material comfortable \\
\hline MC & \\
\hline S & \\
\hline T & \\
\hline
\end{tabular}

Through analysis, it is found that the essential factors of outdoor fitness facilities are concentrated on the basic functions and safety. At present, the outdoor fitness facilities in the market are various and fully functional. From the analysis of the single fitness facilities, it can meet the demands of adult fitness and has better safety, but it cannot meet the demands of children, the elderly and the disabled. Some children will use adult fitness equipment. But often there is a safety accident because the size and intensity are inappropriate. The expected factor is the decisive factor in the development of outdoor fitness facilities and reflects the user's expectation of new products. It is mainly embodied in two aspects: meeting the demands of different crowds of people's health requirements and emotional requirements. Functional charm factors are some of the features that make users more unexpected. It is found that these functions are focused on the interaction between products and people, such as virtual coaches offered by fitness facilities, intelligent networking, energy recovery, movement analysis, and friends circle communication.

\section{Outdoor Fitness Crowd Appeal Analysis}

Through the analysis based on Kano model, we can find out that the fitness crowd's feeling and the potential demand for the outdoor fitness facilities. We conducted further interviews with certain important appeals, then identify opportunities for outdoor fitness facilities. as shown in Figure II.

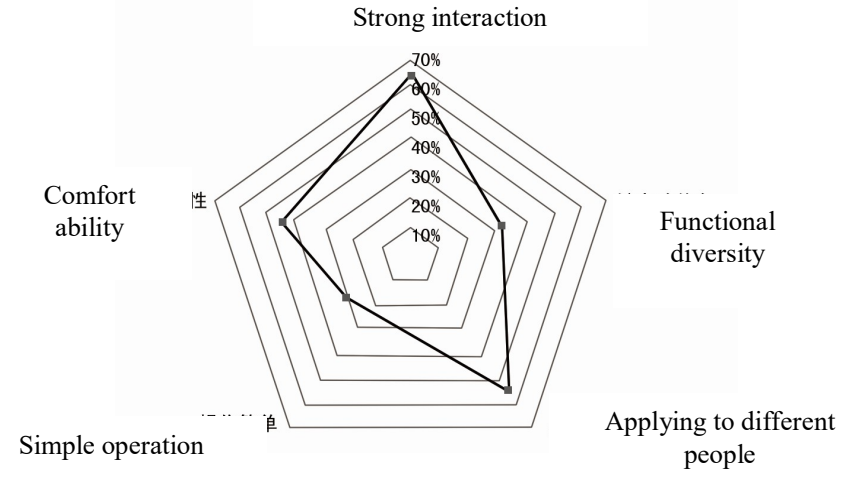

FIGURE II. DEMANDS ANALYSIS OF OUTDOOR FITNESS CROWD

Through depth interviews, it was found that the vast majority of users expected to design fitness facilities according to different crowds' physical characteristics and fitness requirements. Children and the elderly expect to have dedicated fitness facilities. Most of the outdoor fitness facilities in the market are for healthy adults. But fitness facilities for children, the elderly and the disabled are rare. In reality, the use of fitness facilities is very chaotic. Security, pertinence and fitness effect are unsatisfactory. The survey found that people's demand for outdoor fitness facilities changed from pure fitness function to emotional experience and spiritual comfort.

\section{INNOVATIVE DESIGN IDEAS OF OUTDOOR FITNESS FACILITIES}

Through the analysis of Kano model and user demands, the outdoor fitness facilities will develop new human-computer interaction facilities, interactive fitness facilities and special fitness facilities to meet the new demands of fitness crowd, improve satisfaction.

\section{A Human-Machine Interaction Fitness Facilities}

Human- machine interaction fitness facilities refer to an interaction between the fitness person and the fitness facilities. The variability of facilities in a certain extent to meet the emotional requirements of individual fitness. The variability of facilities includes movable, adjustable, variable, audible, etc[1]. In order to achieve the interaction between people and products, the operation of the product should be concise and clear.

Interpersonal interactive fitness facilities

Interpersonal interactive fitness facilities that are 
associated with folks particularly on the fitness actions affect the other for the one's action. As they're connected, they have to coordinate with each other and finish the fitness activities. The fitness facilities contact with person and person through the common experience and touch their affections, to cause their mental response and satisfy the emotional demand of those who are intoxicated with fitness ${ }^{[4]}$.

\section{B Specialized Fitness Facilities}

Specialized fitness facilities are designed by the age, the body feature and the mental characteristic of the special crowd, to satisfy the exercise requirement of the different crowd, such as the children, the youth, the elderly, the disabled and so on ${ }^{[5]}$.

\section{The Designing Scheme OF OUtdoor Fitness FACILITIES BASED ON KANO MODEL}

Four outdoor fitness facilities were designed in the interactivity and the specialized fitness facilities according to the major requirement of the user.

\section{A The Designing of the Solar Human-machine Interactive Fitness Facilities}

The solar human-machine interactive fitness facilities are capable to interact and communicate with the fitness crowd in the field of the voice guidance, music player, information feedback, etc. When the fitness person is prepared to fitness, the infrared inductor installed in the interaction system will feel the people and send the signal to control unit. At the same time, the control unit determines that there are people around the fitness device, opening the music player, hinting the exerciser after proper operation how to play the same rhythmic music as the fitness actions and causing the information such as exercise time feed back to the exerciser in time. When the fitness person finishes and leave, the infrared inductor will feel the person' $\mathrm{s}$ departure, sending a signal to control unit again, at the same time it will judge that there is no person and quit music player to save energy ${ }^{[6]}$.

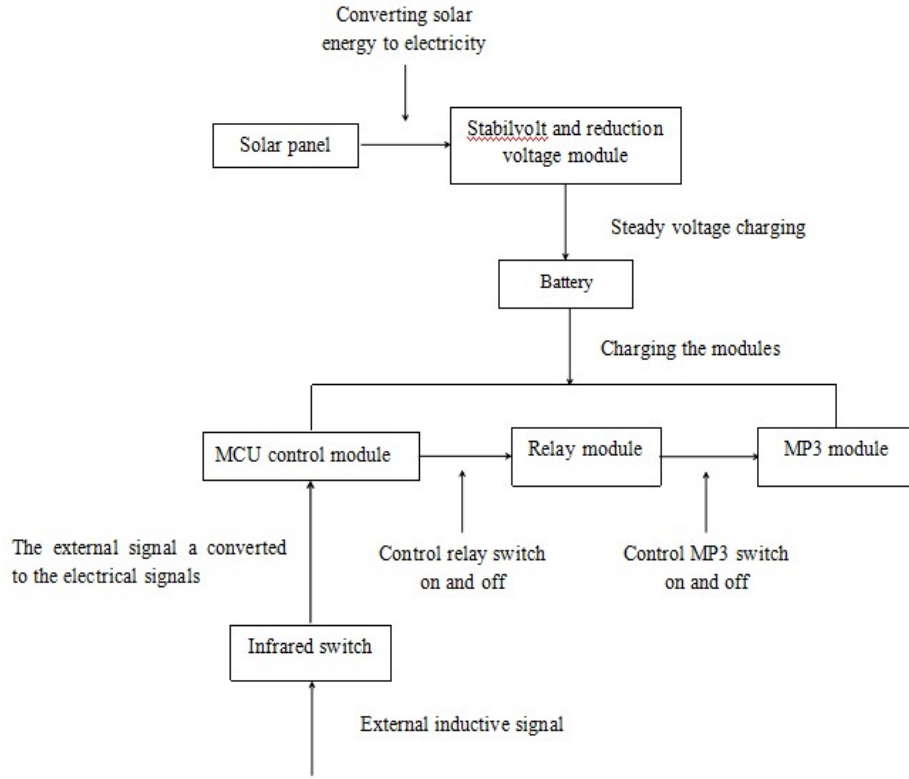

FIGURE III. THE HUMAN-MACHINE INTERACTION MODULE
To fit the existing fitness facilities and decrease the cost of new product development, the interactive model is installed on a solo subject, and the existing facility will be installed between the two sides of the subject. The structure design of the solar human-machine interactive fitness facility is shown in figure IV take a fitness bike as an example.

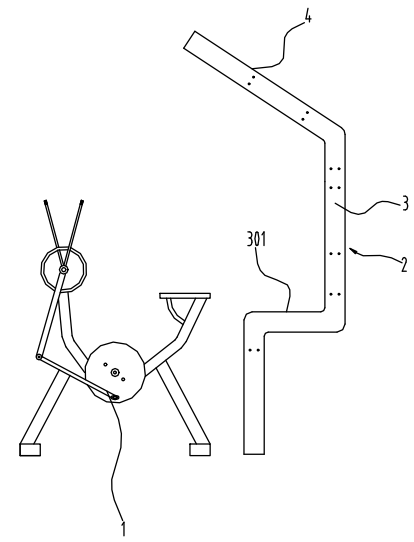

1 the fitness module; 2 the installation body; 3 man-machine interactive module installation position, 301 level table; 4 solar power module

FIGURE IV. THE STRUCTURE DIAGRAM OF SOLAR INTERACTION FITNESS FACILITIES

This designing using the stationary fitness bike as a case, its fitness module guarantees the interactive position. Let the assembly unit of the human-computer interactive module such as inductor, music player and so on install on the position 3 , assuring its sensitivity and the effect of voice playing. Figure $\mathrm{V}$ shows that the same fitness bike can be placed on both sides, both sides are installed sensor switch, can be human-computer interaction. We can also put two different fitness facilities on both sides, both sides are installed sensor switch, can be human-computer interaction.

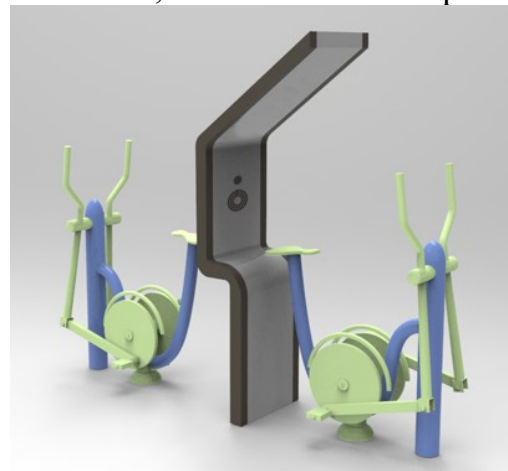

FIGURE V. TEH RENDING OF SOLAR INTERACTION FITNESS FACILITIES

\section{B Paternity Fitness Facilities Design}

The paternity fitness facilities mainly address the problem of the adult and the child(particularly baby) go out together but not exercise together. Because of the different age of a child with different interactive demand and different sports skills. 
This thesis proceeded a designing discussion with the child' $\mathrm{s}$ two age crowd.

\section{1)The paternity sitting tensioner}

This designing scheme locates the child's age in $1 \sim 3$ and the age orientation of the adult is $18 \sim 50$. The children on this stage requirement to be looked after by the adult who is not able to keep fit. This kind of paternity fitness facility connects with taking care of children and keeping fit. Its exercise movement and interaction with children is the major of this kind of facility. The structure diagram is shown in Figure VI and VII.

Put the infants into the infants' fitness bag 2 and adult should sit on the fitness chair 4, two hands grasping the handles of the connecting rod 9; The mechanism are driven by the adult sitting on the chair when he or she pulls the handles upward and downward through connecting rod 9, by the third pivot pin 8 , transmitting the energy onto the folding connecting rods 7 , the second pivot pin 5 and adults fitness chair 4, which makes the fitness chair 4 as well as the infants in the infants' bag move upward and downward by the cord pull 3. This mechanism works in this way that makes infants happy.

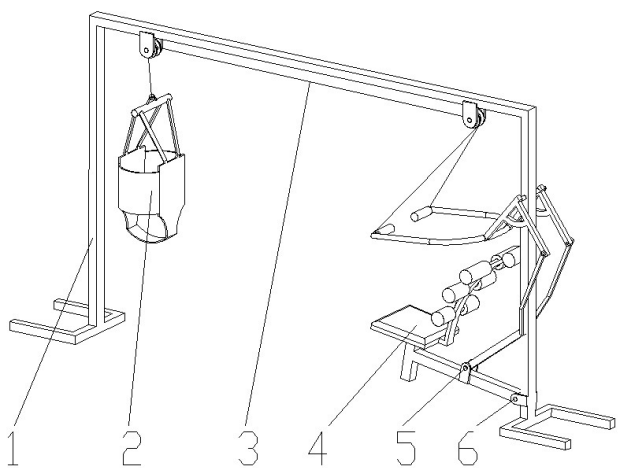

1 frame; 2 pulling bag; 3 pulling rope; 4 adult bodybuilding chair; 5 second driving pin; 6first driving pin

FIGURE VI. PATERNITY SITTING TENSIONER STRUCTURE

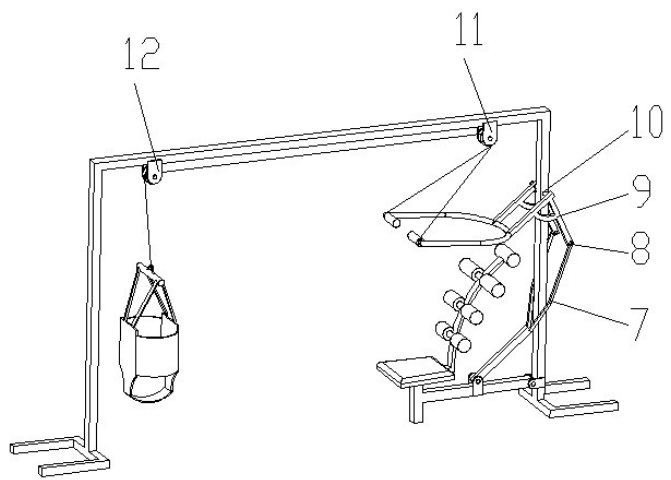

FIGURE VII. PATERNITY SITTING TENSIONER STRUCTURE

7 bow connecting rod; 8 third turn pin; 9 armrest integral connecting rod; 10 fourth turn pin; 11 first definite pulley;

12-second definite pulley

2)The design of paternity interactive fitness bike
The paternity interactive fitness bikes locate the child's age in 4 8 and the age orientation of the adult is $18 \sim 60$ and above. A child's athletic ability, cooperative ability and stand-alone capability are strengthening from three years old, while the children from 4 to 8 years old are fond of sports actions of little range, expecting to play some interactive game what they can do with their parents. Aim to the characteristic of this age stage of the children, designing the parenting interactive stationary bikes. The effect diagram is shown in figure VII.

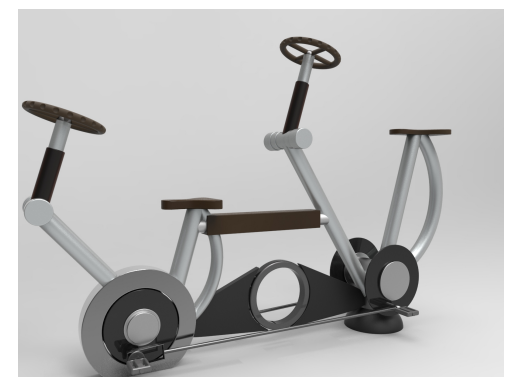

FIGURE VIII. PATERNITY INTERATIVE FITNESS BIKE

The paternity interactive fitness bikes are based on the existing stationary bikes, setting two sizes of pedaling construction. The adult cooperates the child to fitness together, this process of common participation reduces the fatigue and boredom of the movement, relieves boredom, boring, negative emotions, and forms a good fitness atmosphere. They not only enhance the communication between parents and children but also promote interpersonal interaction and satisfy folks' emotional demand. Taking safety into considering, the child's seat is put into the sight of the adult, being easy to adjust the pedalling speed and embodying the higher level care for people.

The comfort level depends on the relative position between the rider and the bicycle's handle, saddle and pedal. Therefore, the relative position of the rider's hands, hips and feet in the bicycle is a key determinant of fitness. When riding, the body should be tilted slightly forward 15 degrees. The maximum angle of the knee joint cannot exceed 150 degrees, at least 65 degrees. The upper arm and lower arm bending angle of about 20 degrees. The exact size is based on the body size of the adult and 4-8 year- old child. ${ }^{[7]}$

\section{The Designing of the Outdoor Fitness Bike for Children}

Most of existing children's outdoor fitness facilities are "shrinkage" of adult's, children's body size, exercise load norm, psychological tailored were not considered, so the fitness effect is unsatisfied, there will be a security accident.

So designing a specialized fitness facilities for children is becoming the new requirement of the user. The stationary bike is the fitness facility used by the children. This thesis proceeded an improved design using the outdoor fitness bike for children as an example. 


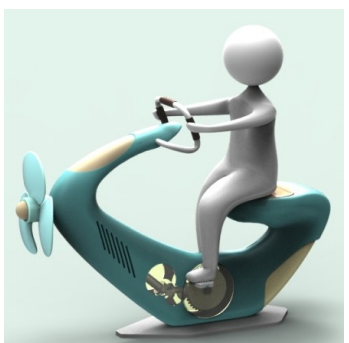

FIGURE IX. OUTDOOR FITNESS BIKES FOR CHILDREN

The design is based on the theory of ergonomics and the children's physical morphological characters, according to the physical morphological characteristics of children and adolescents aged 7-18 think the design of main structural dimensions including length design of cranks is between 118 $177 \mathrm{~mm}$ and adjustment size is $59 \mathrm{~mm}$; to design linear distance from saddle to the central axis of the crank is between 346 $595 \mathrm{~mm}$; angle of the line which from saddle to the crank shaft center and the horizontal plane is 75 degrees while riding, the maximum vertical dimensions adjustment of the saddle and handlebar is $241 \mathrm{~mm}$, straight-line distance from the saddle to handlebar design can be adjusted in $540 \sim 1104 \mathrm{~mm}$ and the size is $282 \mathrm{~mm}^{[7]}$.

The process of the fitness experience is designed into the process of the game experience combining the children' mind of favoring game. In the front of the fitness bike adding turntable fan connecting the pedal with shaft rotation, riding will push the forward fan to rotate whose speed is determined by the riding rate. In addition, part of the body using a transparent acrylic material to facilitate children to see the gear working conditions and working principle, the model applies the appearance with strong appetency and without sharp corner designing, avoiding hurt in the casual circumstance.

\section{CONCLUSION}

Based on the Kano model theory, this paper analyses the fitness experience and potential demands of the fitness crowd, and point out that the interaction and special fitness facilities are the central requirements of the users. So design practice was carried out, including solar interactive fitness facilities, paternity fitness facilities, fitness facilities for children. The solar human-machine interactive fitness facilities had made a prototype and finished the further verification for their solar skills and interactive function. The paternity fitness facilities mainly studied their fitness function and the method of application, which needed to further study the trouble of load measure and so on. The subject of the specialized fitness facilities discussed the fitness facilities design for children using the fitness bike for children as an example. Although the study that had been mentioned above has a value of theory support for the study of fitness facilities, its content is not comprehensive, only providing thinking of research and development. The actual $R \& D$ process still needs to conduct specific studies of several details.

\section{ACKNOWLEDGEMENT}

Thank you very much, AMEE2017 is able to provide such a platform for you to learn and exchange. In the process, my team and I have benefited a lot. And Fund project: Outdoor Health Industry Product Design and Development; Hebei Province Science and Technology Plan (no. : 15275702 d).

\section{REFERENCE}

[1] Yin Bing,Research on Humanized Design of Outdoor Fitness Equipment,Master Thesis of Jilin University,2008,P7

[2] Feng Weiwei, Li Yusheng, Xin Xiangyang Improved Design of Family Fitness Vehicle Based on Kano Model [J],Machine Design,thirty-second volume, eighth issue, 2015.8

[3] Feng qing, Yu Suihuai, Yang Lei,Modeling Design of Emergency Communication Vehicle Based on Kano Model [J], Machine Design, thirty-second volume, ninth issue, 2015.9

[4] Yi Yanli, Interactive Design of Outdoor Fitness and Entertainment Facilities[D], Dissertation for graduate students of Southwest Jiao Tong University, 2010.10, P23-40

[5] Kang Hui, Chen Mo, Xu Haoran, Improvement and Application of Community Fitness Equipment[J], Packaging Engineering, 2013 issue 11,Vol. 34 No.22:55-56

[6] Hu Yunyan, Zhang Ruiying, Wang Jun, Development Status and Prospect of Solar Photovoltaic Power g\Generation in China [J]. Journal of Hebei University of Science and Technology, February 2014 Vol. 35 No.1

[7] He Shenjie, Chen Liang, Cai Rui, Progress in Research and Development of Fitness Equipment for Children and Adolescents, May 2013, Thirty-fourth volumes of Physical Education and Science, third issue P97 